\title{
Spatial factors in metacon trast*
}

\author{
LESTER A. LEFTON \\ University of South Carolina, Columbia, South Carolina 29208
}

\begin{abstract}
Different mask ring widths, intercontour distances, mask durations, and interstimulus intervals were varied in a parametric manner. Results show decreasing amounts of metacontrast with increases in intercontour distance, and no significant effects of mask width or mask duration. The results provide support for monotonic metacontrast functions with maximum metacontrast at the off set of the target.
\end{abstract}

Metacontrast is the phenomenal suppresion of one stimulus when followed by a second visual stimulus when the stimuli are nonoverlapping and fall within a critical time period. This literature has recently been reviewed by Kahneman (1968) and by Lefton (1972). Metacontrast has been explained by a number of theoretical positions; among them, however, the concept of lateral inhibition has been most prominent. The present experiment examines metacontrast under conditions which might maximize and minimize the extent of lateral inhibition in an attempt to examine the general lateral inhibition model of metacontrast.

Purcell, Stewart, and Dember (1968) have used the concept of lateral inhibition to explain metacontrast. This model is presented in its entirety by Purcell et al (1968) and has been summarized and reviewed (Lefton, 1972). In a masking paradigm, Purcell et al suggest that one consider two groups of cells, Group 1, those neurons upon which a black target impinges, and Group 2, those neurons upon which a bright surround impinges. In the dark-adapted eye, with the presentation of a target stimulus, there will be a differential amount of inhibition generated. The Group 1 cells will not generate much activity at all; Group 2 cells will fire and produce inhibition. Group 1 and Group 2 neurons become differentially susceptible to a homogeneous masking flash because of the differential in inhibition generated. Since Group 1 is uninhibited when a masking flash is presented, it will fire at relatively high rates; Group 2 is "transformed from an area of relatively high rates of firing to an area of relatively low rates of firing [Purcell et al, 1968, p. 344]." Upon presentation of a homogeneous masking flash, there will be three possible outcomes, each dependent on the amount of differential inhibition created. If the differential is large, then when stimulated by a masking flash, Group 1 cells will fire much more than Group 2 cells, and an integration of the two flashes will result in a brightness reversal of the target figure. With less of a differential, the amount of firing of the stimulus and the surround will be very close-the target will be indistinguishable from the surround. An even smaller differential will allow the target to appear darker or black, relative to the

*I thank Snow Donmoyer and Joseph Schumpert for their help in testing Ss, and John Byrnes for his help in data analysis. background. In a detection task, only the third alternative allows the S to say, "Yes, I saw the target."

Metacontrast can be explained in an extension of the model of masking (Purcell et al, 1968). For metacontrast in a detection task, the amount of firing of Group 1 neurons must be raised to some level such that a differential of the right amount is made to create a homogeneous field or a brightness reversal. To create this differential, a black area might be introduced into the masking flash. This area could "protect" the areas around the ring from the buildup of lateral inhibition to the level of that expected from a homogeneous field. Those neurons adjacent to the black areas can thus fire at a rate higher than they might have when a homogeneous mask was presented, with the result being a lack of detection or a brightness reversal. The model explains metacontrast by arguing that the ring in a disk-ring sequence acts to protect the stimulus from the spread of lateral inhibition, particularly at the shorter onset asynchronies.

To investigate this notion, Purcell et al (1968) and Cox and Dember (1971) attempted to measure the spatial effectiveness of a mask. They estimated the width of the spatial effectiveness of a mask to-be about $12.18 \mathrm{~min}$ of arc. These results are different, however, from those reported by Davidson (1968), who found that the responses on one side of a bright line were about 5 min of arc. Taylor (1958) found, based on the calculations of Beitel (1936), the width of an inhibitory zone on one side of a line to be $10 \mathrm{~min}$ of arc, while Békésy (1960) has suggested $6 \mathrm{~min}$ of arc. Inhibitory zones might have different widths under different stimulus conditions, however, such as the strength of the excitatory signal from the original stimulus (Ratliff, 1965).

The present experiments attempt to examine the model of Purcell et al (1968). According to Purcell et al and Cox and Dember (1971), if the stimulus is over 20 min of arc away from a mask, the mask should have no effect. With the stimulus size held constant, a manipulation was made of intercontour distance in an attempt to assess this prediction. Furthermore, Purcell et al have suggested that the black areas in a masking ring act to protect the target from the spread of lateral inhibition. If this assumption is true, then there should be a potent effect of manipulations of the width of the 
masking ring. There should also be a significant interaction of the width of a masking ring and the intercontour distance. Two of the main variables in the present study were intercontour distance and the width of the masking ring.

A reasonable prediction, based on the model of Purcell et al (1968), is that at short interstimulus intervals with narrow mask width there should be monotonic metacontrast functions. As the ring becomes wider. it can act to stop the spread of lateral inhibition, and thus $U$-shaped functions should be produced as the ring is delayed. Furthermore, this change in shape of the function should vary as intercontour distance is varied. Both of the measures, the width of the ring and intercontour distance, can examine to some extent the spread of the suppression in metacontrast and test whether the spread of this effect goes beyond the boundary of $20 \mathrm{~min}$, as suggested by Cox and Dember (1971).

\section{METHOD}

\section{Subjects}

The author, two graduate assistants, and three undergraduates, who were paid volunteers, served as Ss. All had normal or corrected vision.

\section{Stimuli and Apparatus}

The stimuli were presented in a Gerbrands four-field tachistoscope (Model $\mathrm{T}-4 \mathrm{~B}$ ). The disks that served as targets were $.93 \mathrm{~cm}$ in diam, and were drawn with black India ink on white cards. At a distance of $86 \mathrm{~cm}$, they subtended an angle of $.6 \mathrm{deg}$. Two targets were drawn and placed in different fields of the tachistoscope, one that would fall in the center of the right masking ring, the other to fall in the center of the left ring. The stimuli were drawn such that the center-to-center distance was $4 \mathrm{deg}$. The masking stimulus contained two annuli drawn side by side from the same ink as the targets. The annuli were varied in width, such that the distance between the inner diameter of the annulus and the outer diameter corresponded to five different widths, $.10, .20, .30, .40$, and $.50 \mathrm{deg}$. The distance between the outside measurement of the target and the inside measurement of the mask was also varied. This intercontour distance was 0 , $.10, .20, .30$, or $.40 \mathrm{deg}$. There were 25 different masking cards arranged. Each card represented one of the 25 possible conditions of a factorial combination of the five different intercontour distances and the five mask ring widths.

\section{Procedure}

Upon introduction to the laboratory, each $S$ was read instructions about the nature of the stimuli and task and told that on each trial he was to respond by indicating whether the target had been presented to the left or the right of the centrally located fixation spot. Ss were encouraged to stare at the fixation spot before initiating a new trial. After 5 min of dark adaptation and 10 practice trials, the session formally began. Each $\mathrm{S}$ served for 26 sessions, the first session being practice. The remaining 25 sessions were each devoted to one of the 25 mask ring width-intercontour distance combinations. The order of the presentation of the 25 conditions was randomized. Each $S$ received either this same random order or the exact reverse of that order, thus achieving counterbalancing of the conditions across experimental sessions.
Since there were two possible positions of the target, two targets were drawn and each one aligned in one of the masking rings so that the intercontour distance was equal on all sides. All stimuli were presented monocularly to the right eye. The target stimuli were always presented for $10 \mathrm{msec}$, at a luminance of $2 \mathrm{fL}$, which matched the background luminance of the other fields. Following the target, there was an interstimulus interval of $0,20,40,60,80$, or 100 msec. This interval was filled by the light fixation field. The masking rings followed and were presented for either 50 or 200 msec.

The experimental conditions were arranged in blocks of 14 trials. The first 2 trials within each block were practice, the remaining 12 were a random ordering of the six interstimulus intervals with a left and right presentation of the target. There were 14 blocks of trials, with alternating blocks of trials presenting the mask for 50 or $200 \mathrm{msec}$. Ss were told before each block of trials that there would be a change in the mask duration. On any one session, therefore, each $S$ would receive 168 experimental trials, half of which were at one mask duration and the other half at the second mask duration. Each of the interstimulus intervals would be tested twice within a block. At the end of an experimental session, each $S$ would have contributed 14 measurements to each of the interstimulus interval-mask duration combinations.

\section{RESULTS}

The number of errors for each experimental condition for each $\mathrm{S}$ was computed and entered into an analysis of variance (Duration by Ring Width by Intercontour Distance by Interstimulus Interval by Ss). There were strong effects of delaying the mask, with increases in accuracy as the mask was delayed, $F(5,25)=24.6$, $\mathrm{p}<.001$. Increasing the intercontour distance showed dramatic increases in accuracy, $\mathrm{F}(4,20)=20.5, \mathrm{p}<.001$. Neither ring width nor the duration of the ring showed significant main effects. There was a strong Intercontour Distance by Interstimulus Interval interaction, $F(20,100)=20.7, p<.001$, which is clearly evident in Fig. 1. There were two other significant interactions: the Ring Width by Interstimulus Interval, $F(20,100)=1.9$, $\mathrm{p}<.05$, and the multiple interaction of Duration by Ring Width by Intercontour Distance by Interstimulus Interval, $F(80,400)=1.8, p<.001$. These two interactions account for $.5 \%$ and $1.6 \%$, respectively, of the overall variability in the experiment compared with $18 \%$ and $15 \%$ for the significant main effects. The individual data points for all of the functions are presented in Table 1. Figure 1 presents the data collapsed over duration and ring width; the parameter on the curve is intercontour distance.

\section{DISCUSSION}

There was a failure to find any significant differences due to the duration of the mask. Even when the mask was presented for a duration four times as long, the results were essentially the same. There would most likely have been significant differences due to duration were the mask durations employed below $90 \%$ threshold. 
Although the data presented by Kaswan and Young (1963, 1965) might allow a prediction of the results of manipulations of mask duration, manipulations of the width of a mask might produce changes in the shapes of function obtained. The model proposed by Purcell et al (1968) suggests that the ring in a metacontrast paradigm acts to "protect" the stimulus from lateral inhibition, particularly at the short interstimulus intervals. Manipulations of the width of a masking ring should therefore change the extent to which the target stimulus is masked. In the present experiment, the width of the masking ring was manipulated between $.10 \mathrm{deg}$ of visual angle and $.50 \mathrm{deg}$ of visual angle, and there was no overall effect $(F<1)$. Inspection of the data in Table 1 clearly shows five overlapping functions which have a narrow range. The dramatic effects that may be predicted by the model of Purcell et al were not obtained. Growney and Weisstein (1972) have recently found that changes in mask ring width beyond about $.05 \mathrm{deg}$ showed no increases in metacontrast, but that a smaller mask width did show a dramatic decrease. The present results therefore are not at variance with those of Growney and Weisstein (cf. Matteson, 1969).

Purcell et al (1968) have made predictions about the extent of masking effects with manipulations of intercontour distance. Many experiments have shown dramatic increases in accuracy with increases in intercontour distance (e.g., Alpern, 1953: Cox, Dember, \& Sherrick, 1969: Kolers \& Rosner, 1960). As is clear from Fig. 1, increases in intercontour distance showed systematic increases in accuracy, such that by $.30 \mathrm{deg}$,

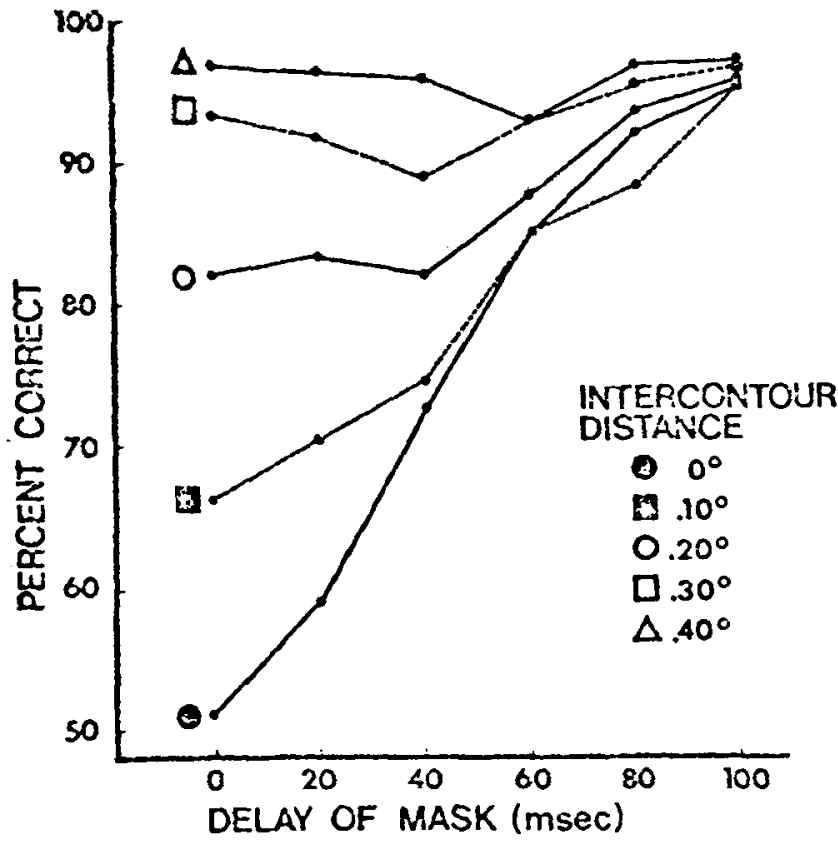

Fig. 1. The mean percentage of targets that were reported correctly is plotted as a function of the delay of the mask. The data have been collapsed across mask ring width and mask duration. The parameter on the curve is intercontour distance. Each data point represents the mean of $\mathbf{8 4 0}$ observations.
Table 1

Errors Collapsed Across Subjects and Mask Duration

\begin{tabular}{|c|c|c|c|c|c|c|c|}
\hline \multirow{2}{*}{$\begin{array}{c}\text { Inter- } \\
\text { contour } \\
\text { Distance }\end{array}$} & \multirow{2}{*}{$\begin{array}{l}\text { Ring } \\
\text { Width }\end{array}$} & \multicolumn{6}{|c|}{ Interstimulus Interval } \\
\hline & & 0 & 20 & 40 & 60 & 80 & 100 \\
\hline \multirow[t]{2}{*}{0} & $\begin{array}{l}.10 \\
.20 \\
.30 \\
.40 \\
.50\end{array}$ & $\begin{array}{l}5.7 \\
7.2 \\
7.3 \\
7.4 \\
6.5\end{array}$ & $\begin{array}{l}5.8 \\
5.3 \\
6.2 \\
6.0 \\
5.3\end{array}$ & $\begin{array}{l}3.8 \\
4.0 \\
3.8 \\
3.8 \\
3.3\end{array}$ & $\begin{array}{l}1.8 \\
2.2 \\
2.1 \\
2.1 \\
1.9\end{array}$ & $\begin{array}{l}0.8 \\
1.1 \\
1.2 \\
1.5 \\
0.7\end{array}$ & $\begin{array}{l}0.5 \\
0.3 \\
0.6 \\
0.9 \\
0.4\end{array}$ \\
\hline & Mean & 6.8 & 5.7 & 3.7 & 2.0 & 1.1 & 0.5 \\
\hline \multirow[t]{2}{*}{.10} & $\begin{array}{l}.10 \\
.20 \\
.30 \\
.40 \\
.50\end{array}$ & $\begin{array}{l}4.0 \\
4.8 \\
4.5 \\
4.3 \\
6.0\end{array}$ & $\begin{array}{l}4.7 \\
4.8 \\
2.8 \\
3.9 \\
4.4\end{array}$ & $\begin{array}{l}3.1 \\
3.6 \\
3.6 \\
3.8 \\
3.4\end{array}$ & $\begin{array}{l}2.2 \\
1.9 \\
2.0 \\
2.3 \\
1.9\end{array}$ & $\begin{array}{l}1.8 \\
1.4 \\
1.9 \\
1.3 \\
1.5\end{array}$ & $\begin{array}{l}0.7 \\
0.8 \\
0.5 \\
0.5 \\
0.1\end{array}$ \\
\hline & Mean & 4.7 & 4.1 & 3.5 & 2.0 & 1.6 & 0.5 \\
\hline \multirow[t]{2}{*}{.20} & $\begin{array}{l}.10 \\
.20 \\
.30 \\
.40 \\
.50\end{array}$ & $\begin{array}{l}0.9 \\
2.0 \\
3.5 \\
3.1 \\
2.7\end{array}$ & $\begin{array}{l}1.8 \\
2.1 \\
2.5 \\
2.7 \\
2.4\end{array}$ & $\begin{array}{l}2.2 \\
3.0 \\
2.7 \\
2.2 \\
2.4\end{array}$ & $\begin{array}{l}1.0 \\
1.8 \\
1.5 \\
2.5 \\
1.5\end{array}$ & $\begin{array}{l}0.6 \\
0.8 \\
1.0 \\
1.2 \\
0.5\end{array}$ & $\begin{array}{l}0.6 \\
0.5 \\
0.3 \\
0.7 \\
0.4\end{array}$ \\
\hline & Mean & 2.4 & 2.3 & 2.5 & 1.7 & 0.8 & 0.5 \\
\hline \multirow[t]{2}{*}{.30} & $\begin{array}{l}.10 \\
.20 \\
.30 \\
.40 \\
.50\end{array}$ & $\begin{array}{l}1.0 \\
1.0 \\
0.5 \\
0.4 \\
1.5\end{array}$ & $\begin{array}{l}2.0 \\
0.9 \\
0.5 \\
1.1 \\
1.3\end{array}$ & $\begin{array}{l}2.5 \\
1.6 \\
0.9 \\
1.3 \\
1.1\end{array}$ & $\begin{array}{l}1.0 \\
1.0 \\
0.9 \\
0.6 \\
1.1\end{array}$ & $\begin{array}{l}0.9 \\
1.2 \\
0.2 \\
0.4 \\
0.2\end{array}$ & $\begin{array}{l}0.5 \\
0.5 \\
0.0 \\
0.7 \\
0.1\end{array}$ \\
\hline & Mean & 0.9 & 1.1 & 1.5 & 0.9 & 0.6 & 0.4 \\
\hline \multirow[t]{2}{*}{.40} & $\begin{array}{l}.10 \\
.20 \\
.30 \\
.40 \\
.50\end{array}$ & $\begin{array}{l}0.1 \\
0.2 \\
0.8 \\
0.3 \\
0.8\end{array}$ & $\begin{array}{l}0.1 \\
0.5 \\
0.8 \\
0.5 \\
0.5\end{array}$ & $\begin{array}{l}0.1 \\
0.4 \\
0.8 \\
0.5 \\
0.7\end{array}$ & $\begin{array}{l}1.0 \\
0.9 \\
1.4 \\
0.3 \\
1.0\end{array}$ & $\begin{array}{l}0.1 \\
0.2 \\
0.9 \\
0.0 \\
0.6\end{array}$ & $\begin{array}{l}0.0 \\
0.1 \\
0.7 \\
0.4 \\
0.6\end{array}$ \\
\hline & Mean & 0.4 & 0.5 & 0.5 & 0.9 & 0.4 & 0.4 \\
\hline
\end{tabular}

Note-Maximum number of errors $=14$

performance was at an asymptotic level. This result is consistent with the estimates made by Cox and Dember (1971), who argued that the spatial effectiveness of a mask is about $30 \mathrm{deg}$. They are somewhat in contrast to those provided by Weisstein and Growney (1969) and by Alpern (1952), who found that metacontrast could be obtained even at 1 to $2 \mathrm{deg}$ of visual angle. These results also differ from those reported by Growney and Weisstein (1972), who reported a spatial effectiveness of about $.16 \mathrm{deg}$. This disparity in results may, however, be a function of exact stimulus sizes, luminance levels, and even more important task differences.

The decrease in the extent of metacontrast with increases in intercontour distance was not just an overall decrease in sensitivity. If this were the case, then the functions obtained for each of the different intercontour distances would have been of similar slope and have a different $y$-intercept. Although the $y$-intercept did differ, the slopes of the functions are clearly very different. This finding was supported by the Intercontour Distance by Interstimulus Interval interaction. The effect of increasing the intercontour distance was to decrease the extent of metacontrast, but particularly at the shorter interstimulus intervals. At the longer 
interstimulus intervals. the functions have a similar slope-however, these functions do not becrin similar until at least a $40-\mathrm{msec}$ interstimulus interval. It might be argued that if lateral inhibition is the process that is creating metacontrast, the amount of time for the mask to act can be estimated by these data. The data suggest that, with an increase in intercontour distance of even $.10 \mathrm{deg}, 40 \mathrm{msec}$ are required for the mask to act in a manner similar to when the mask and target are exactly adjacent.

The experiment examined part of the model put forth by Purcell et al (1968). The present study found support for the extent of the spatial effectiveness of the mask. However, it failed to support the contention that with increases in the mask diameter, particularly at the shorter interstimulus intervals, there would be changes in the shape of metacontrast functions obtained. The model of Purcell et al is based on the notion of brightness reversals, and, indeed, they have evidence that these reversals do take place. However, Eriksen, Becker, and Hoffman (1970) have argued that the brightness of a test stimulus may be independent of its recognition accuracy: both Schurman (1972) and Lefton (1972) have argued the same point. Task differences may create different results, yet models that have been posited have generally not considered this factor.

\section{REFERENCES}

Alpern. M. Metacontrast. Journal of the Optical Society of America. 1953, 43, 648-657.

Beitel. R. J. Inhibition of threshold excitation in the human eye. Journal of General Psychology, 1936, 14, 31-61.

Békésy. G. von. Neural inhibitory units of the eye and skin. Quantitative description of contrast phenomena. Journal of the Optical Society of America, 1960, 50, 1060-1070.

Cox. S. I.. \& Dember, W. N. Effect of target field luminance, interstimulus interval, and target mask separation on extent of visual backward masking. Psychonomic Science, 1971, 22, 79-80.

Cox, S. I., Dember, W. N., \& Sherrick, W. F. Effect of backward masking on spatial separation between target and mask contours on target size. Psychonomic Science, 1969, 17. 205-206.

Davidson. M. Perturbation approaches to spatial brightness interaction in human vision. Journal of the Optical Society of America, 1968, 58, 1300-1308.

Eriksen, C. W., Becker. B. B.. \& Hoffman, J. E. Safari to masking land: A hunt for the elusive U. Perception \& Psychophysics. $1970,8.245-250$.

Growney, R., \& Weisstein. N. Spatial characteristics of metacontrast. Journal of the Optical Society of America, $1972,62,690-696$.

Kahneman, D. Method, findings, and theory in studies of visual masking. Psychological Bulletin. 1968, 70, 404-425.

Kaswan, J., \& Young, S. Stimulus exposure time, brightness and spatial factors as determinants of visual perception. Journal of Experimental Psychology, 1963, 65, 113-123.

Kastvan. J., \& Young, S. Effect of luminance, exposure duration and task complexity on reaction time. Journal of Experimental Psychology, 1965, 69, 393-400.

Kolers, P. A.. \& Rosner, B. S. On visual masking (metacontrast): Dichoptic observation. American Journal of Psychology: 1960, 73. 2-21.

Lefton, L. A. Metacontrast: A review. Psychonomic Monograph Supplements, 1972, 4(14, Whole No. 62). Republished: Perception \& Psychophysics. 1973, 13, 161-171.

Matteson, H. H. Effect of surround size and luminance on metacontrast. Journal of the Optical Society of America. 1969, 59, 1461-1468.

Purcell, D. G.. Stewart, A. L., \& Dember, W. N. Spatial effectiveness of the mask: Lateral inhibition in visual backward masking. Perception \& Psychophysics, 1968. 4. 344-346.

Ratliff, F. Mach bands: Qualitative studies on netural networks in the retina. San Francisco: Holden Day, 1965.

Schurman, D. L. Predictive validity of a Rashevsky-Landahl neural net: Test of a model of masking for form. Perception \& Psychophysics, 1972, 12, 183-186.

Taylor, W. K. Visual organization. Nature, 1958, 182, 69-70.

Weisstein, N., \& Growney, R. L. Apparent movement and metacontrast: A note on Kahneman's formulation. Perception \& Psychophysics, 1969, 5, 321-328.

(Received for publication April 14, 1973: revision received July 18,1973 .) 